\title{
Gestão pedagógica das escolas da rede estadual de ensino do Paraná - descrição dos aspectos empresariais e burocráticos de organização e sistematização
}

Eliane dos Santos Macedo Oliveira ${ }^{1}$

\begin{abstract}
Resumo:
Este texto trata de uma pesquisa descritiva e bibliográfica que está atrelada às experiências funcionais e do exercício da profissionalidade da autora como coordenadora pedagógica de escolas da rede estadual de ensino do Paraná. Estas experiências são cotejadas com as discussões realizadas por estudiosos das políticas educacionais que analisam as formas pelas quais os processos de gestão educacional são construídos. Neste texto recorrer-se-á aos aportes teóricos que se direcionam às compreensões de Neoliberalismo e a adoção de prerrogativas empresariais no modo como o pensamento e a prática educativa são projetadas no cotidiano da gestão escolar. Buscou descrever, brevemente, o processo de implantação das tutorias pedagógicas nas escolas da rede estadual de educação, a partir do ano de 2019, com o intuito de reverter índices insuficientes relacionados a avaliações externas e outros aspectos avaliativos e metodológicos, que podem ser identificados como mecanismos para tornar a gestão pedagógica das escolas em um espaço gerencial aos moldes da estruturação de empresas.
\end{abstract}

\author{
Palavras-chave: \\ Gestão Escolar. Educação. Neoliberalismo. Empresarial.
}

\section{Pedagogical management of Paraná state schools - descrip- tion of business and bureaucratic aspects of organization and systematization}

\begin{abstract}
:
This text is a descriptive and bibliographical research that is linked to the functional experiences and the exercise of the author's professionality as pedagogical coordinator of schools in the Paraná state education system. These experiences are collated with the discussions carried out by scholars of educational policies who analyze the ways in which educational management processes are constructed. This text will resort to theoretical contributions that address the understanding of Neoliberalism and the adoption of business prerogatives in the way educational thinking and practice are projected in
\end{abstract}

1 Mestra em Educação, professora no Colégio Estadual Rancho Alegre, PR. E-mail: esmacedo879@gmail.com ORCID iD: https:// orcid.org/0000-0002-7523-6558 
the daily life of school management. It sought to briefly describe the process of implementing pedagogical tutoring in schools in the state education network, from the year 2019, with the aim of reversing insufficient indices related to external evaluations and other evaluative and methodological aspects, which can be identified as mechanisms to turn the pedagogical management of schools into a managerial space similar to the structuring of companies.

Keywords:

School Management. Education. Neoliberalism. Business.

\section{Gestión pedagógica de las escuelas públicas de Paraná: descripción de los aspectos empresariales y burocráticos de la organización y sistematización}

\section{Resumen:}

El presente texto es una investigación descriptiva y bibliográfica que se vincula a las experiencias funcionales y al ejercicio de la profesionalidad del autor como coordinador pedagógico de las escuelas del sistema educativo del estado de Paraná. Estas experiencias se cotejan con las discusiones llevadas a cabo por estudiosos de las políticas educativas que analizan las formas en que se construyen los procesos de gestión educativa. Este texto recurrirá a aportes teóricos que abordan la comprensión del neoliberalismo y la adopción de las prerrogativas empresariales en la forma en que el pensamiento y la práctica educativos se proyectan en la vida cotidiana de la gestión escolar. Se buscó describir brevemente el proceso de implementación de la tutoría pedagógica en las escuelas de la red educativa estatal, a partir del año 2019, con el objetivo de revertir índices insuficientes relacionados con evaluaciones externas y otros aspectos evaluativos y metodológicos, que se pueden identificar como mecanismos para convertir la gestión pedagógica de las escuelas en un espacio gerencial similar a la estructuración de empresas.

Palabras clave:

Gestión escolar. Educación. Neoliberalismo. Negocio.

\section{Introdução}

Compreender a educação escolar e seus processos sistemáticos na sociedade contemporânea, requer situar, no campo das discussões e estudos das políticas educacionais, a conjuntura em que ela se encontra. Estudos evidenciam que as políticas educacionais são, desde 1990, influenciadas pelo ideário neoliberal, que, segundo alguns estudiosos, pressupõe uma retomada de aspectos liberais para a gestão social. Como alternativa para uma época em crise, as perspectivas do pensamento e práticas neoliberais foram amplamente difundidas, principalmente a partir do Consenso de Washington, em 1989, em que organismos reguladores financeiros passaram a ditar regras para que países em desenvolvimento conseguissem quitar as suas dívidas. Civiatta e Frigotto (2003) afirmam que essas prerrogativas foram orientadoras das reformas sociais elaboradas durante a década de 1990.

Na mesma direção, Libâneo, Oliveira e Toschi (2007) apontam que as diretrizes neoliberais amplamente acatadas por diversos países na década de 1990 tinham como matrizes básicas a formulação de uma economia cujo mercado se assentasse na livre concorrência, tendo como pressupostos motrizes a competitividade, a eficácia e qualidade. Outro ponto relevante corresponde à atuação do Estado mínimo para o fortalecimento e crescimento da economia. Prosseguindo neste viés, além das medidas fiscais requeridas para o alavanque da economia, outro aspecto passou a 
ser requerido, correspondente à formação de um perfil de trabalhador apto a atender as prerrogativas em voga. Surgiu a tendência atrelada aos princípios de polivalência, adaptação, flexibilidade e aptidão para adquirir habilidades e conhecimentos cognitivos, emocionais, pessoais e outros, capazes de garantir a ascensão no e do mercado.

Nesta direção as prerrogativas neoliberais direcionam o pensamento da educação como um espaço de lucratividade, sendo o local de preparação de sujeitos com conhecimentos básicos e essenciais às demandas que emergem e são ditadas pelo mercado. Cattani (2002) pontua o papel da escola enquanto formadora de profissionais capazes de aumentar a produtividade. Afirma, a partir da Teoria do Capital Humano, que cabe a cada indivíduo analisar as condições de custos e benefícios atrelados à construção de seu "capital pessoal", com base nos investimentos lançados para garantir a sua formação e posterior remuneração. Sobre este aspecto da formação do "capital humano" Facci (2004) acrescenta que, embora os indivíduos sejam levados a encarar a sua formação enquanto processo que poderá beneficiar e permitir a sua empregabilidade, não significa que o mercado irá absorver a sua força de trabalho, tendo em vista que não há espaço para todos. Por outro lado, esta autora pontua que as exigências de contínua adaptabilidade "jogam nas costas" do trabalhador a incapacidade de não acompanhar as mudanças essenciais impostas pelo mercado.

Para Demo (2005), o neoliberalismo condiciona e molda o processo educacional, precarizando suas intencionalidades pedagógicas e formativas. O debate crítico cede lugar para a impossibilidade do saber pensar. Para Saviani (2007), a escola teria a função de garantir a formação de pessoas capazes de desenvolver a habilidade do "aprender a aprender", estando continuamente em busca de conhecimento e técnicas, além de manifestarem comportamentos flexíveis que lhes permitam adaptar-se às demandas do mercado.

Ao considerar a conjuntura neoliberal de inserção dos processos escolares, este texto tem como finalidade expor, brevemente, algumas reflexões referentes à organização da gestão escolar, com um recorte voltado aos aspectos pedagógicos, aqui situados no campo da orientação de professores e a organização do processo de ensino-aprendizagem.

\section{As tutorias pedagógicas}

A escolha deste recorte, pautada pela pesquisa bibliográfica e descritiva, tem como fomento a minha vivência profissional como coordenadora pedagógica de escolas da rede estadual de ensino do Paraná. Há muito percebo a precarização do trabalho e a alocação de mecanismos empresariais para o direcionamento das práticas escolares. Chamo atenção para o projeto de tutorias pedagógicas que, inicialmente, foi implementado em 1.100 escolas da rede, com a justificativa de que estas estavam com baixos índices em avaliações externas e números elevados de reprovação e abandono escolar. Neste percurso, o projeto de tutoria pedagógica foi ampliado a todas as escolas da rede, tendo como objetivo

[...] melhorar o processo de ensino e aprendizagem, combater o abandono escolar e diminuir os índices de reprovação na rede estadual de ensino [...], qualificar os diretores e pedagogos e proporcionar aos professores subsídios para elaborar uma boa aula com foco no aprendizado dos alunos. (PARANÁ, 2019).

Tecnicamente, a dinâmica do projeto consiste na visita regular de tutores (funcionários dos Núcleos Regionais de Educação - NREs) a cada semana com a equipe gestora das escolas (diretores, diretores auxiliares e pedagogos) para analisarem os indicadores da escola, tais como: abandono escolar, distorção idade/série, índices em avaliações externas, índices de notas bimestrais, entre outros processos pertinentes à dinâmica escolar. Atreladas à verificação destes dados, sempre são 
estabelecidas metas semanais. Ao se diagnosticar um número elevado de notas abaixo da média em uma determinada disciplina, por exemplo, a meta estabelecida sugere (recomenda) que as equipes intervenham e revertam o cenário apresentado. Metas a longo prazo como a elaboração de planos de aula com sequências didáticas por cada docente, a observação de aulas por parte dos pedagogos, que devem conferir teoria/prática da ação docente, entre outras, também são estipuladas.

Embora muitas destas ações sejam praticadas e desenvolvidas pelos pedagogos no exercício da gestão escolar, os discursos proferidos condicionam a autonomia da escola que, continuamente, são levadas a apresentar e superar metas estabelecidas pela Secretaria de Estado da Educação (SEED). Recorrentemente, o trabalho pedagógico tem se direcionado à análise de descritores de avaliações externas com menor número de acerto, sendo continuamente debatidos em formações pedagógicas, por vezes, disfuncionais. A organização do tempo e espaços pedagógicos muitas vezes deve ater-se à superação de percentuais. Neste ponto, identifico o que Freitas (2018) reporta como Movimento Global da Reforma Educacional. Conforme o autor, neste movimento ocorre a transposição de características dos espaços empresariais para a gestão escolar, tais como: a padronização em diversos processos "na e da educação", priorização de processos que buscam desenvolver habilidades e conhecimentos voltados à áreas específicas, determinação de metas de aprendizagem, a sistematização de um processo de ensino assentado em resultados pré-determinados, entre outros aspectos que demonstram a pressão e controle por resultados a partir do ranqueamento e culpabilização dos agentes educacionais envolvidos nestes processos.

A gestão dos processos pedagógicos, assentada nestas prerrogativas, torna o trabalho fundamentado, em parte, no paradigma gerencial contemporâneo e, em outras, no modelo de administração pública burocrática, discutido em Brasil (1995). Toma emprestado da gestão burocrática aspectos como a garantia do poder do Estado, direcionado ao formalismo e ao poder racional-legal que prevê o controle rígido dos processos e ao atendimento de demandas. Do paradigma gerencial, agrega características como as inspirações de administração das empresas, sobretudo em aspectos como a avaliação sistemática e a recompensa por desempenho. Percebe-se que a estrutura de gestão pedagógica requerida pela SEED, desde 2019, descaracteriza o trabalho pedagógico, sobretudo, quando agrega elementos empresariais não sintonizados com percepções críticas de educação. A centralização das decisões direcionadas ao cumprimento de metas, o controle das práticas docentes e o acompanhamento (fiscalização) destes processos, podem esfacelar a gestão democrática que aos poucos se manifesta decadente. A estas discussões soma-se a ruptura de identidade dos pedagogos, que, além de terem suas cargas de trabalho aumentadas, estão continuamente incluídos em práticas discursivas do "vestir a camisa" e "fazer parte do time" e outras que lhes confere um título de "gerente da escola".

Evangelista (2005), Libâneo (2002, 2006), Libâneo e Pimenta (1999), Silva (2004) e outros, há anos debatem a identidade profissional dos pedagogos. Pontuam que por décadas é debatido a qual ramificação profissional devem pertencer os licenciados em pedagogia. Aos poucos, diante da estruturação excessivamente técnica a nós imposta, percebe-se que a nossa identidade declina para aquela dos anos 1970, de fiscalizador que, conforme esclarece (SILVA, 2008), era o responsável pela formação do "capital humano" e que se responsabilizaria pelo controle do processo escolar aos moldes do que se consolidava nas fábricas.

\section{Considerações Finais}

Estamos imersos em uma rotina de gestão escolar que dificulta o nosso trabalho e nos impõe a função de garantir o aumento de indicadores, o sucesso em avaliações externas e a controlar o processo pedagógico que deve condicionar os professores ao cumprimento de variadas metas estabelecidas. Somos parte de uma engrenagem que, muitas vezes, tende a alienar o nosso trabalho, pois há muitos interesses capitais envolvidos em discursos como os anunciados pela SEED, atre- 
lados aos ditos progressos tecnológicos como Livro Registro de Classe Online (LRCO), aplicativos variados para a correção de avaliações externas e outros mecanismos conferem a nosso trabalho uma identidade burocrática e nos impõem uma carga excessiva de tarefas que pouco a pouco, vão demonstrando o quanto o mercado coloca suas garras na educação. Com base na análise da forma como os objetivos e estruturação das tutorias pedagógicas procuram se consolidar, percebe-se o controle e práticas empresariais cada vez mais agregadas ao processo educativo, o que pode, a longo prazo, ferir os pressupostos de autonomia pedagógica das escolas. Além destes, destaca-se as nuances veladas por estes discursos e práticas, que visam a formação de um perfil estudantil alinhado aos interesses do mercado contemporâneo. Em suma, as descrições e reflexões aqui problematizadas não esgotam a temática e sinalizam a necessidade de aprofundamento em outros estudos que se dedicam às políticas educacionais.

\section{Referências}

BRASIL. Plano Diretor da Reforma do Aparelho do Estado. Brasília, DF: Presidência da República, 1995.

CATTANI, Antonio David. Dicionário crítico sobre trabalho e técnica. 4. ed. Porto Alegre: UFRGS; Petrópolis: Vozes, 2002. DEMO, Pedro. A educação do futuro e o futuro da educação. Campinas: Autores Associados, 2005.

EVANGELISTA, Olinda. Curso de Pedagogia: propostas em disputa. [S. l.: s. n.], 2005. Disponível em: http://www.ced. ufsc.br/pedagogia/Textos/OlindaEvangelista.htm. Acesso em: 14 jun. 2011.

FACCI, Marilda Gonçalves Dias. Valorização ou esvaziamento do trabalho do professor? Um estudo crítico comparativo da teoria do professor reflexivo, do construtivismo e da psicologia Vigotskiana. Campinas: Autores Associados, 2004.

FREITAS, Luiz Carlos de. A reforma empresarial da educação: nova direita, velhas ideias. São Paulo: Expressão Popular, 2018.

FRIGOTTO, Gaudêncio; CIVIATTA, Maria. Educação Básica no Brasil na década de 1990: Subordinação Ativa e Consentida à Lógica do Mercado. Educação \& Sociedade, Campinas, v. 24, n. 82 p. 1-360, abr. 2003.

LIBÂNEO, José Carlos. Diretrizes Curriculares da Pedagogia: Imprecisões teóricas e concepção estreita da formação profissional de educadores. Educação \& Sociedade, Campinas, v. 27 n. 96, out. 2006.

LIBÂNEO, José Carlos. O que é pedagogia, quem é o pedagogo, o que deve ser o curso de pedagogia. Conferência no Fórum de Educação “Pedagogo: que profissional é esse?”. Belo Horizonte: Revista Gestão Universitária, 2002.

LIBÂNEO, José Carlos; OLIVEIRA, João Ferreira de; TOSCHI, Mirza Seabra. Educação Escolar: políticas, estrutura e organização. 4 ed. São Paulo: Cortez, 2007.

LIBÂNEO, José Carlos; PIMENTA, Selma Garrido. Formação de profissionais da educação: visão crítica e perspectiva de mudança. Educação \& Sociedade, Campinas, ano 20, n. 68, dez. 1999.

PARANÁ. Tutoria Pedagógica: novo projeto ajuda escolas estaduais no desenvolvimento da gestão escolar e ações pedagógicas. Paraná: SEED, 2019. Disponível em: http://www.educacao.pr.gov.br/Noticia/Tutoria-Pedagogica-novo-projeto-ajuda-escolas-estaduais-no-desenvolvimento-da-gestao. Acesso em: 23 ago. 2020.

SAVIANI, Demerval. História das ideias pedagógicas no Brasil. Campinas: Autores Associados, 2007.

SILVA, Carmem Silva Bissoli da. Curso de Pedagogia no Brasil: História e Identidade. Campinas: Autores Associados, 2004.

SILVA, Fabiana dos Santos Franco da. A identidade do Pedagogo e as novas Diretrizes Curriculares de Pedagogia. [S. l.: s. n.], 2008. Disponível em: http://www.pucpr.br/eventos/educere/educere2008/anais/pdf/167_519.pdf. Acesso em: 5 jun. 2011.

Data de submissão: 09/11/2020

Data de aceite: 12/01/2021 